\title{
Gendered Influence of Downward Social Comparisons on Current and Possible Selves
}

\author{
Markus Kemmelmeier* and Daphna Oyserman \\ University of Michigan
}

Because men and women differ with regard to independent and interdependent self-construals, we propose that downward comparisons are more likely to lower women's achievement-related self-evaluations compared to men's. We also hypothesize that gendered self-schemas provide men with advantages in the processing of self-related dispositional information and women with advantages in the processing of self-related social-contextual information. To the extent that a downward social comparison presents a potential threat to the self, men and women differ in how effectively they can fend off the implications of different types of comparisons. Results from three experiments (total $\mathrm{N}=393$ ) support these hypotheses, suggesting that gendered responses to downward comparison are at least in part driven by a culturally normative focus on dispositional information prevalent in the West.

When focused on stereotypically "female" tasks, women expect to succeed (Lenney, 1981; Stein, Pohly, \& Mueller, 1971). Unfortunately, this self-confidence fades in stereotypically "male" achievement domains (Lenney, 1977; Maccoby \& Jacklin, 1974). In spite of comparable levels of actual performance on specific tasks, women are less confident than men (Bornholt, Goodnow, \& Cooney, 1994) and tend to underestimate their performance (Beyer, 1990) in these "male" domains.

\footnotetext{
*This research was funded in part by a Faculty Scholar's Award to the second author from the W. T. Grant Foundation. The preparation of this manuscript was supported by an ISR Founders dissertation grant and by a grant from the University of Michigan Department of Psychology to the first author. An earlier version of this work was presented at the 1995 Meeting of the American Psychological Society, New York. We would like to thank Rose Foster for assisting in data collection in Study 1 and Jessica Cameron for her help in collecting the data in Study 2. Many thanks also to Janet Swim for her helpful editorial comments.

Correspondence concerning this article should be addressed to Markus Kemmelmeier, Department of Psychology, University of Michigan, Ann Arbor, MI 48109-1109 [e-mail: markusk@umich.edu].
} 
This lack of perceived competence undermines persistence and motivation and can lower women's overall achievements (Brown \& Dutton, 1995; Weiner et al., 1987; Zuckerman, 1985). Eventually, lower levels of achievement provide apparent corroboration of sexist stereotypes of women as less competent and contribute to the continued stigmatization of women, especially in high-achievement domains.

In the present article, we propose that this cycle is perpetuated in part because women's gender socialization emphasizes relatedness, so that women are more likely to think in these situated terms, a way of thinking not well suited to the Western cultural paradigm of individualism. Using this theoretical approach we explore gender-specific consequences of downward social comparisons and examine how cultural assumptions about causes of failure and differences in the self-concepts of men and women interact to produce lower levels of academic self-competence in women.

\section{Implications of Downward Social Comparisons}

In school and academic settings students usually know who is doing well and who is doing poorly: Grades may be posted, students look at one another's papers, and everyone notices who fails to show up at school anymore. What are the implications of learning about another person's failure for assessment of one's own current and future academic competence? Most social-comparison theories assume that a comparison with a worse-off other provides people with an opportunity for self-enhancement as another's misery makes one's own situation look more promising (Brickman \& Bulman, 1977; Hakmiller, 1966; Wills, 1981), especially if failure in the domain could undermine self-competence or self-worth (Tesser, 1988). Thus, downward comparisons tend to improve one's outlook and increase one's confidence (e.g., Gilbert, Giesler, \& Morris, 1995; Pelham \& Wachsmuth, 1995). Social comparisons also serve people's needs for accurate self-assessment (Festinger, 1954), however, and taking the failure of another person into account may provide diagnostic information about potential dangers and pitfalls facing the self (Trope, 1986). Hence, rather than giving rise to self-enhancement, information about a worse-off other may spark a realistic reassessment and downward adjustment of one's own chances of success and failure. A downward adjustment may be especially likely when the other is viewed as similar to the self and one feels a sense of connection with the other (Buunk \& Ybema, 1997).

\section{Gender and Self-Schemas}

We propose that the choice between downward and upward adjustment given a social comparison is at least to some degree gendered and follows from genderspecific differences in underlying structure of the self-concepts. A plethora of research shows that men and women tend to differ with regard to how much they 
define themselves as autonomous agents versus view themselves as connected to and embedded in relationships with others (e.g., Bakan, 1966; Cross \& Madson, 1997; Gilligan, 1982; Helgeson, 1994; Lykes, 1985; Markus \& Oyserman, 1989). Men are more likely to have independent self-construals that focus on personal uniqueness, self-determination, and personal agency. Among other things, this leads to a more pronounced tendency to self-enhance. For example, men overestimate the degree to which their own characteristics and abilities are unique and unshared by others (Goethals, Messick \& Allison, 1991). Men also tend to be more overconfident about their performance (Beyer, 1990) and boastful of their accomplishments (Heatherington et al., 1993).

By comparison, women are more likely to have interdependent self-construals that focus on the self as contextualized and embedded in relationships with others. For example, women are more interested in their relationships (Acitelli, 1993), pay more attention to others (Ickes, Robertson, Tooke, \& Teng, 1986), and recall more information about others with whom they share a relationship (Josephs, Markus, \& Tafarodi, 1992). In general, compared to men, women are more likely to be sensitive to others' feelings, to empathize with them, and to be responsive to others' feedback (Dunn, Bretherton, \& Munn, 1987; Roberts, 1991; Schwalbe \& Staples, 1991; see Cross and Madson, 1997, for a comprehensive review of gender differences in independence and interdependence).

These gender differences in self-construals are accompanied by gender differences in self-schemas, that is, knowledge structures accessed in processing of information relevant to the self (Catrambone \& Markus, 1987; Markus, 1977; Markus \& Sentis, 1982; Markus, Smith, \& Moreland, 1985). Specifically, because women tend to focus more on social contexts and relationships, they are likely to have a rich conceptual structure pertaining to these aspects of their own and other people's behavior. Conversely, because men habitually focus on individual uniqueness, they are more likely to focus on person characteristics and dispositions when considering their own and other people's behavior and are likely to have richer knowledge structures in this domains. These differences in the complexity and availability of self-related knowledge structures can be compared to having "expertise" in the processing of trait and dispositional information or in the processing of contextual and relational information (Markus et al., 1985). It is plausible that men and women's self-schemas are likely to affect how they process self-relevant information pertaining to social context and dispositions.

\section{Consequences for Downward Social Comparison}

We propose that differences in how men and women organize self-knowledge will influence how self-relevant information is processed when men and women engage in a social comparison with another person. First, because previous research has shown that women define themselves through their relationships with 
others, they are more likely to empathize with a worse-off other, even though this may lower their own self-evaluations. Second, men's focus on personal uniqueness should lead them to view a downward comparison as an opportunity for selfenhancement. Rather than elicit empathy, another person's misery is likely to highlight men's own superior qualities, and, hence, elevate their own self-evaluations. Third, because women's self-schemas make them more sensitive to contextual factors (Cross \& Madson, 1997; Oyserman \& Markus, 1989), we predict that the degree of the self-other similarity will help shape the degree to which a downward comparison lowers women's self-evaluations. Women should be very likely to empathize when the worse-off comparison other is similar to them and thus adjust their own self-views downward. When the comparison other is dissimilar to the self, however, the downward shift in self-views should be should be less pronounced (cf. Buunk \& Ybema, 1997). By contrast, the degree of similarity or difference between self and a worse-off other should be inconsequential for men's self-views, because men are less sensitive to contextual factors, and because men may view any downward comparison as an opportunity for self-enhancement.

\section{The Cultural Context of Self-Construals}

Although the idea of gender differences in self-construals is widely accepted, the literature has not sufficiently explored the interplay between larger cultural frame and gender-specific self-construals. Thus, although men and women may generally be socialized to make sense of themselves and their everyday world in terms of independence and interdependence, respectively, they are both embedded in a larger cultural frame. In the United States, this cultural frame focuses on individualism (e.g., Triandis, 1995). That is, institutional practices and patterns of social interactions bolster a view of the individual as an independent, even self-contained, entity that can determine its own fate and has stable traits and characteristics (Oyserman \& Markus, 1993; Sampson, 1977). In American academic settings, for example, testing and tracking typically assumes that individuals have stable levels of intelligence and that this stable personal characteristic is critical to academic success (Stevenson \& Stigler, 1992).

Generally, individualism as a cultural construct has been associated with a preference for person-focused causal reasoning (Norenzayan, Choi, \& Nisbett, 2000; Oyserman, Coon, \& Kemmelmeier, 2000). That is, causes are assumed to lie in fixed dispositions, traits, and characteristics. Conversely, interdependence or collectivism is associated with greater sensitivity to situational and contextual factors and a tendency to conceive of others in terms of their social contexts and relationships (J. G. Miller, 1984; Morris \& Peng, 1994; Shweder \& Bourne, 1984). Thus, men and women socialized within such an individualistic cultural frame should favor dispositional information over social-contextual information, especially when evaluating and explaining performance or achievements (Stevenson \& 
Stigler, 1992). Although this dispositional focus in the achievement domain may be shared between men and women, this does not preclude that men and women differ in their self-schemas and in whether they have richer knowledge structures for the processing of dispositional or social-contextual information. It is clear that even in the context of an individualist culture gendered socialization patterns differentially emphasize self-construals (and self-schemas) as independent or interdependent (Kashima et al., 1995; Watkins et al., 1998).

The expertise associated with independent and interdependent self-schemas has implications for how individuals can protect their own sense of self from potentially depressing implications of a downward comparison. Assuming that both men and women strive toward maintaining some degree of positive self-regard in the face of threat, they are motivated to discount downward social comparisons that have the potential of lowering their own self-evaluations. Even though people may not be able to escape the immediate implications of social-comparison information for their self-evaluations, more extensive processing helps individuals to "fend off" the negative implications of the comparison, for example, by questioning its applicability or diagnosticity for the self (cf. Gilbert et al., 1995).

We propose that rich knowledge structures facilitate this process of "fending off" the negative implications of downward comparisons for the self. Men and women should be differentially efficient at reducing the impact of a threatening downward social comparison depending on whether the comparison involves a contrasting of personality traits and dispositions or whether it involves the contrasting of life situations and contexts. Men should be better able to avoid the negative implications of downward comparison when the comparison focuses on traits and dispositions, whereas women should be more efficient at fending off downward comparisons that focus on social contexts. In sum, we hypothesize that men's and women's independent and interdependent self-construals aid in self-regulation when confronted with threatening downward comparison. Whether deflecting a potentially threatening downward comparison is successful, however, is contingent on whether the comparison is focused on dispositional or social-contextual information. Because in the United States, the cultural frame seems to favor the former over the latter type of information, there is the potential that overall women are less successful in avoiding the negative consequences of being faced with a failing other.

\section{The Present Series of Studies}

To investigate possible gendered effects of downward comparisons, we conducted a series of studies in which participants were asked to bring to mind someone they knew who was failing academically. Given that graduation rates at many high schools and colleges hover at about 50\%, such downward comparisons may be chronically accessible (Halperin, 1998; L. S. Miller, 1995). We utilized a 
self-generated comparison rather than a standard target to increase ecological validity, that is, to ensure that targets were relevant to, and perceived as failing by, the participants themselves. It also meant that we could manipulate perceived target similarity to and difference from the target independently from the nature of target (see also Tesser and Campbell, 1980). After bringing to mind someone they knew who had failed academically, participants in our studies were instructed to focus either on similarities or differences between the self and the "failed" other (a direction-of-comparison manipulation). We expected this cognitive manipulation to create a temporary processing bias, making either similarities to or differences from the target salient in working memory (see Trafimow, Triandis, \& Goto, 1991).

In Study 1, we predicted that men would be more likely to contrast themselves to a failed other and that women would be more likely to assimilate the other's failure into their self-view. Study 2 examined whether men or women were more vulnerable to negative social comparisons when primed to utilize information incongruent in type to their dominant information processing schema. Finally, Study 3 examined achievement-related causal uncertainty as a potential mediating factor for these gender differences.

\section{Study 1}

Our purpose in Study 1 was to examine whether thinking about another's failure has different consequences for men and women. We predicted that bringing to mind a relevant other's failure would lower women's, but increase men's, satisfaction with their own academic performance. Second, the extent to which these differential outcomes occur for men and women should be moderated by the perceived similarity to the comparison target. Specifically, for women, the dampening effect of another's failure should be particularly pronounced when similarity to the other is salient, not when difference from the other has been made salient. Conversely, we expected that since men are less sensitive to the specific nature of the relationship with the other, they will be likely to view any downward comparison as an opportunity to enhance the self, whether or not they have been asked to think of similarities to or differences from the other.

\section{Method}

Design. We used a two-factor between-participants design with Gender (men vs. women) $\times$ Direction of Comparison (no comparison control, similarities to vs. differences from target).

Participants. Sixty Wayne State University undergraduates (38 women, 22 men) participated as part of course requirements (average age $=20.5 ; 51 \%$ Black, $41 \%$ White, and $8 \%$ other ethnic groups). 
Procedure. Sessions held 1 to 6 participants; each participant worked alone and was self-paced, following instructions and materials in an ordered booklet. Upon completion, participants were thanked, debriefed, and dismissed. In the control condition, participants were simply asked the dependent measure; in the experimental conditions, they were first asked to think of someone they knew who was doing very badly at school and might even fail/had failed and describe that person in a few words (failed comparison target). Participants then described ways they were similar to the target (similarities salient condition) or different from the target (differences salient condition).

Dependent measure. Satisfaction with "how you are doing in school" was rated on a five-point scale, ranging from 0 (very dissatisfied) to 4 (very satisfied).

\section{Results}

Are women more sensitive to the nature of academic comparisons? We expected that women's and men's satisfaction with their performance would be differentially influenced by a downward social comparison. Women's tendency to assimilate the other's failure into their own performance should be most pronounced when similarities to the failed other were made salient and less pronounced when thinking about differences from the failed other. Men, in contrast, would be more satisfied with their own performance compared to a no-comparison baseline, regardless of whether they thought about differences from rather than similarities to a failed other. Because an omnibus analysis does not test these specific hypotheses, we used planned contrast analyses. For a direct test of our predictions we assigned the following weights: for women, control 1, similarities salient -1 , differences salient 0 , and for men, control -2 , similarities salient +1 , differences salient +1 .

As can be seen in Table 1, in general women did adjust downward and men did adjust upward following a downward comparison. The proposed planned comparisons were significant for women, $t(35)=1.99, p=.05$, but not for men, $t(19)=1.41$, $p<.19$. Further, pairwise comparisons corroborated that women were sensitive to the specific nature of the comparison. When similarities with the failed person

Table 1. Satisfaction With Own School Performance After Comparison With a Failed Other (Study 1)

\begin{tabular}{lccc}
\hline & $\begin{array}{c}\text { No comparison } \\
(n=22)\end{array}$ & $\begin{array}{c}\text { Similarities salient } \\
(n=17)\end{array}$ & $\begin{array}{c}\text { Differences salient } \\
(n=21)\end{array}$ \\
\hline Women $(n=38)$ & $3.40^{\mathrm{a}}$ & $2.57^{\mathrm{b}}$ & $3.31^{\mathrm{a}}$ \\
Men $(n=22)$ & 2.86 & 3.20 & 3.40 \\
\hline
\end{tabular}

Note. Scores range from 0 (very dissatisfied) to 4 (very satisfied). Different superscripts within the same row indicate that means differ at $p<.05$, one-tailed. 
were salient, women tended to be less satisfied with their school performance than women in the control condition $(p<.03$, one-tailed) and women in the differences condition ( $p=.04$, one-tailed). These pairwise comparisons were not significant for men. That is, although the overall pattern of results indicated that downward comparison increased men's satisfaction with their achievement, in this study the difference was not statistically reliable. ${ }^{1}$

\section{Discussion}

Study 1 provides initial evidence that women assimilate negative social comparison information into their sense of self whereas men do not. These findings are congruent with research suggesting that women see others as legitimate sources of information about the self (cf. Roberts, 1991) generally and are more sensitive to social-comparison information in the achievement domain in particular (e.g., Lenney, Gold, \& Browning, 1983). To the extent that women are exposed to others' failures, their own self-confidence is undermined. This can undermine women's aspirations as well as their actual achievement, leading to an apparent confirmation of gender stereotypes and to a continued stigmatization of women.

We do not believe, however, that downward comparisons necessarily lead to downward adjustment for women, but rather that the current results were due to the interplay between how achievement is represented in majority society and men's and women's preferred processing styles. Even though they differ in the richness of their cognitive structures, men and women are equally likely to process academic information dispositionally because dispositional attributions are culturally favored over contextual attributions in gauging reasons for academic success and failure in the United States (Stevenson \& Stigler, 1992). Thus, in Study 1 , women were likely to be using a processing style that was their less preferred style and men were likely to be using a processing style that was their preferred style. In Study 2, we varied the salience of dispositional versus contextual attributions systematically.

\section{Study 2}

Study 2 was designed to replicate and extend the findings of Study 1 . We expected that women would be affected by our manipulation to think about a "similar" or "different" failed other. More importantly, we predicted that whether men and women focused on contextual or dispositional attributions for the failure of the target would have an impact on the extent to which downward comparison lowered

${ }^{1}$ Note that in the control condition, mean satisfaction levels for men and women were not significantly different, $t(20)=1.24, p>.23$. 
self-evaluations. Specifically, because women's self-schemas provide them with a richer conceptual structure when processing contextual information and men's self-schemas provide them with a richer conceptual structure when processing dispositional information, we expect that they are better at fending off a threat to the self when presented with information in their domain of expertise. This implies that downward comparison is more likely to lower self-evaluations when men and women utilize information incongruent with their dominant informationprocessing schema.

We also introduced a distracter task to manipulate the salience of the social comparison, assuming that the low-salience condition is a better model of real-life situations. Others' failures, though accessible, may not be salient when making judgments about one's own chances of success. Our dependent variables were the judged likelihood that one would use efficacious strategies to attain positive academic possible selves (Oyserman \& Saltz, 1993) and actually attain these selves (Oyserman \& Markus, 1990).

\section{Method}

Design. A four-factorial between-participants design was used with gender of participant (men vs. women), focus of comparison (dispositional vs. social context of target), salience of comparison (high vs. low), and direction of comparison (similarities to vs. differences from target) as factors.

Participants. A total of 244 University of Michigan undergraduates (105 men, 139 women) participated in this study for course credit. Average age of participants was 18.9 years; $64 \%$ of participants were European American, $14 \%$ African American, 14\% Asian American, 2\% Latino/a, and 5\% were members of other ethnic groups.

Procedure. As in Study 1, participants worked alone at their own pace using a booklet. Sessions included 1 to 6 other students. Participants worked on the tasks in the order presented, then were debriefed, thanked, and dismissed. First, participants were asked to describe the comparison target - a person they knew who was doing very badly at school and might even fail/had failed.

Focus of social comparison. Then participants were asked either to think about how the target's personality traits and characteristics (disposition focus condition) or the target's experiences and life circumstances (context focus condition) may have contributed to the person's failure. Participants recorded their thoughts on three blank lines.

Direction of social comparison. Participants then described similarities in their own personalities to/differences in their own personalities from the target person's personality traits and characteristics/experiences and life circumstances. 
Salience of social comparison. We varied the elapsed time between the social-comparison stimulus and the dependent measure. High-salience-condition respondents filled out the dependent measures without interruption. Low-salience-condition respondents first spent about 3 min on a series of interpolated tasks that did not contain any reference to achievement.

\section{Dependent measures.}

Measurement of possible selves and strategies. Participants rated the likelihood of three possible selves ("doing well in school," "getting good grades," and "understanding the material in my classes"; $\alpha=.88$ ) and four strategies ("using my time wisely," "handling problems that come my way successfully," "coping well with distractions," and "striving persistently towards my goals"; $\alpha=.80$ ). Using a 10-point rating scale (from 0 to 9), participants rated how likely it was that the possible self or strategy would describe them in the coming year. Scale scores were moderately correlated, $r=.45, p<.05$, and were not significantly different for men and women.

Measurement of perceived similarity. On the following page, participants used a 10 -point scale $(0=$ not at all similar, $9=$ very similar $)$ to rate first whether their academic performance in the coming year would be similar to that of the target, second how similar their personality and the target's were, and third how similar their life experiences and the target's were.

Results

Targets of comparison were gendered. Whereas in Study 1 sex of the comparison other was not assessed, in Study 2 we found that men were much more likely to describe a male comparison target $(82.6 \%)$ than women were to describe a female comparison target $(61.1 \%)$. This asymmetry (binomial test $p<.0001$ ) in spontaneous comparison targets has previously been noted in the literature (e.g., Suls, Gaes, \& Gastorf, 1979). We examined the effects of cross-sex comparisons because an other-sex other may be less self-relevant (cf. Sleeper \& Nigro, 1987); this analysis could not include analysis of cross-sex comparisons for men because only $17 \%$ of the men generated a women as a comparison target.

Using a 2 (sex of comparison target) $\times 2$ (focus of comparison: dispositional vs. context) $\times 2$ (direction of comparison: similarities to vs. differences from) $\times 2$ (salience of comparison: high vs. low) analysis of variance (ANOVA) we found a trend-level multivariate main effect for sex of comparison target, $F(2,113)=2.76$, $p=.07$. Women who brought to mind a woman, rather than a man, who had failed were more likely to assimilate the other's failure. They adjusted their possible selves and strategies down to a greater extent than women who brought to mind a man who had failed. Specifically, women were less confident they would utilize 
effective achievement-related strategies when thinking of a failed women than when thinking of a failed man $(M=6.46$ vs. 6.72$), F(1,114)=5.42, p<.03$, and at trend level, less sure they would attain achievement-related possible selves when thinking of a women rather than a man $(M=7.10$ vs. 7.22$), F(1,114)=2.89$, $p=.11$. These findings suggest that at least for women, same-sex comparisons are more powerful than cross-sex comparisons. Because so few men brought women to mind, we could not effectively control for this effect and so chose instead to focus further analyses on the 76 men and 80 women who generated a same-sex target other.

When does another's failure dampen one's own sense of competence? To examine the influence of social comparisons on academic possible selves and strategies for their attainment, we submitted our dependent variables to an ANOVA that included the four experimental factors, focus (disposition vs. context), direction (similarities vs. differences), salience (high vs. low) of social comparison, and gender of participant.

Possible selves. Bringing to mind similarities to rather than differences from a failed other reduced confidence in reaching "high achiever" possible selves $(M=$ 6.78 vs. 7.23$), F(1,140)=5.13, p<.03$. Although the Gender $\times$ Direction of Comparison interaction was not significant, $F(1,140)=0.77$, separate comparisons of men and women corroborated the results of Study 1 in showing that direction of comparison had an impact for women, but not for men. Women's possible selves were more negative when similarities to, rather than differences from, the failed other were brought to mind ( $M=6.67$ vs. 7.35$), F(1,78)=9.34, p<.004$, whereas this manipulation had no effect for men $(M=6.89 \mathrm{vs} .7 .10), F(1,74)=0.70, p>.40$.

There was also a significant Focus of Comparison $\times$ Gender interaction, $F(1$, $140)=4.80, p<.03$. As is displayed in Figure 1, men perceived themselves more likely to reach their "high achiever" possible selves when disposition rather than context was made salient $(M=7.30$ vs. 6.85$)$, pairwise $F(1,140)=3.68, p<.06$. Conversely, women were more optimistic about attaining these possible selves when context rather than disposition was made salient $(M=7.23$ vs. 6.89$), F(1$, $140)=2.23, p<.14$. For women, inducing dispositional focus increased the likelihood that they would assimilate the other's failure into their own sense of self, downgrading their own academic expectations. For men, inducing contextual focus had this effect. Thus both men and women were more vulnerable to negative social comparisons when primed to utilize information incongruent in type to their dominant information-processing schema.

Strategies for attaining possible selves. A trend-level direction-ofcomparison effect emerged. Thinking about similarities to, rather than differences from, a failed other reduced confidence that one would be able to use effective strategies oneself $(M=6.67$ vs. 7.35$), F(1,140)=4.62, p=.09$. This effect was qualified by a significant Gender $\times$ Direction of Comparison interaction, $F(1,140)$ 


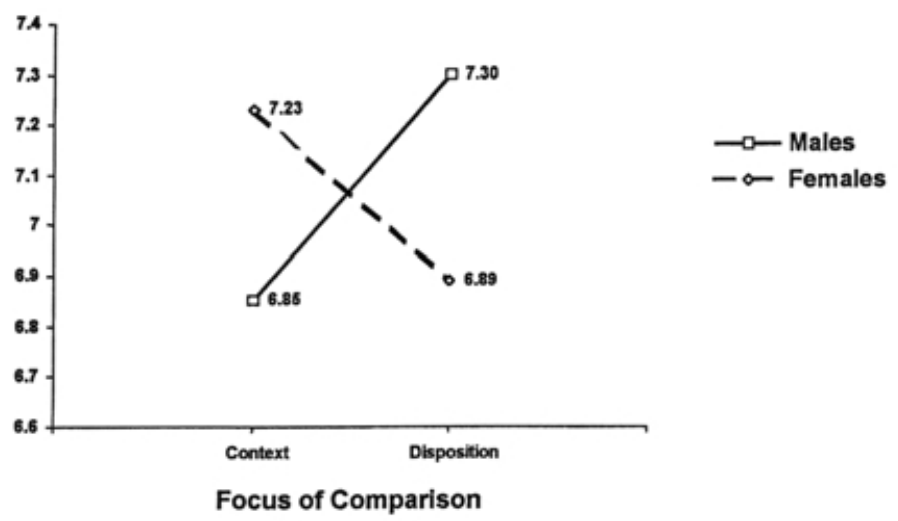

Fig. 1. Likelihood of attaining achievement-related possible selves as a function of focus of social comparison and gender (Study 2).

Note. Ratings were made on a 10-point scale. Higher numbers indicate greater likelihood of attaining one's possible selves.

$=4.24, p<.05$. Women were significantly less sure they would use strategies when a similar rather than a different other's failure was made salient ( $M=5.79$ vs. 6.83$)$, pairwise $F(1,140)=12.60, p<.001$, but no effect emerged for men $(M=6.29 \mathrm{vs}$. 6.22 ), pairwise $F(1,140)=0.02 ; p>.88$. Comparable to the pattern found for possible selves in this study and in Study 1, these results bolster the notion that men are more efficient in using downward comparisons.

Finally, we found a significant Salience $\times$ Focus of Comparison interaction, $F(1,140)=6.30, p<.02$. When participants focused on social context, salient comparisons led participants to be less confident that they would use efficacious achievement-related strategies than when comparisons were disconnected by the filler task $(M=6.60 \mathrm{vs} .6 .01)$, pairwise $F(1,140)=5.04, p<.03$. This result is consistent with the well-known finding that the salience of a stimulus is critical for whether it has an impact on judgment (e.g., Schwarz, 1995). However, when focusing on dispositions, the distracter task had no significant effect ( $M=6.05$ vs. 6.54), pairwise $F(1,140)=2.11, p>.14$.

Perceived similarity. Since the manipulation involved bringing to mind someone known to the target, the similarity judgments were analyzed with the same four-way ANOVA design used throughout to explore whether participants had all brought to mind a comparison other who was equally similar to them in personality and life circumstances; no significant difference was found on these items, suggesting that the participants brought to mind reasonably similar targets. Significant effects emerged only for the perceived similarity between the failed other and one's own future school performance. For this variable, a two-way Salience $\times$ Focus of Comparison interaction, $F(1,138)=6.17, p<.02$, was qualified by a 
three-way Salience $\times$ Focus of Comparison $\times$ Gender interaction, $F(1,138)=8.25$, $p<.006$. Men in the high-salience condition saw themselves as more similar to the failed other in the dispositional than in the contextual focus condition ( $M=3.53 \mathrm{vs}$. $1.83), F(1,138)=7.25, p<.01$, with a reversal when salience was low $(M=1.64$ vs. 3.76), $F(1,138)=8.71, p<.004$. Pairwise comparisons for women were not significant.

\section{Discussion}

Study 2 replicated findings from Study 1 that direction of comparison influences women, not men. When thinking of how they were similar to a failed target, women (but not men) felt less likely to attain their achievement-related possible selves than when they thought about how different they were from this failed other. Study 2 also provided support for our central hypothesis that women and men differ with regard to the richness and efficiency of cognitive structure for the processing of contextual versus dispositional information. Women's belief that they could attain achievement-related possible selves and use efficacious strategies to attain these selves was dampened when they brought to mind another woman's failure, but only in certain conditions. Women in our study assimilated the other's failure into their own futures particularly when thinking of the other's dispositions and personality. They contrasted their own likely future with the other's failure when thinking of the social contexts and circumstances surrounding the other's failure. The opposite occurred for men, who were more likely to assimilate another's failure when thinking about the circumstances rather than the dispositions of the other. We take this as evidence that men and women differ with regard to the efficiency with which they can shield the self from the negative consequence of a downward comparison for the self.

Given the Western cultural focus on achievement as based on disposition rather than an individual's circumstances, women are likely to be at a disadvantage in deflecting the effects of downward comparisons. Typically, downward comparisons in an individualist society can be expected to involve a comparison of dispositions, and as a result women are more likely to assimilate others' failures than men. Indeed, Study 1 showed that when men and women were presented with such a typical downward-comparison situation, women's, but not men's, self-evaluations were negatively affected. Study 2 supported the notion that this gender effect was due to the implicit assumption inherent in the Western cultural frame that an individual's dispositions are responsible for his or her failure to achieve. When failure was framed as due to context, it was men, not women, who were more likely to assimilate another's failure into their judgments of their own future success.

It is possible that the observed differences were due in part to differences between men's and women's sense of causal certainty about how one can attain academic success: Given the dispositional frame used to explain academic failure, 
it can be assumed that men will feel more secure in their judgment of how to attain success and avoid failure in academic contexts, whereas women, given their more contextual processing preference, may feel less certain. Since Study 2 does not provide any information about causal certainty, we examined this variable in Study 3.

\section{Study 3}

We hypothesized that causal certainty, one's subjective sense of understanding the principles that determine success and failure in a domain (Weary \& Edwards, 1994), would be differently triggered for men and women. Dispositional focus would reduce women's causal certainty about academic success, whereas contextual focus would have this effect on men.

\section{Method}

Design. A three-factor between-participants design was used including gender, direction of comparison (similarities vs. differences), and focus of comparison (dispositional vs. contextual).

Participants. Ninety-two University of Michigan undergraduates (39 women, 53 men) participated in exchange for course credit. The average age of participants was 20.1 years. Ethnicity was not assessed but is likely comparable to that in Study 2; that is, participants were likely to be mostly European American.

Procedure. Experimental procedures generally followed those in Study 2: Participants were instructed to think of a same-sex "failed" student target, and their similarities to/differences from the target's traits/life circumstances, then rated their certainty about how to succeed in school.

Measures. The dependent measure was the sum of the three Causal Uncertainty Scale items (Weary \& Edwards, 1994) that refer to school achievement: "When I receive good grades, I usually do not understand why I did so well," "When I receive poor grades, I usually do not understand why I did so poorly," and "When someone I know receives a poor grade, I often cannot determine if he or she could have done anything to prevent it" $(\alpha=.86)$. Participants responded to each item on a 6-point scale with $1=$ strongly disagree and $6=$ strongly agree .

Results

A three-way ANOVA showed main effects of gender, $F(1,84)=6.57, p<.02$, and focus of comparison (at trend level), $F(1,84)=3.77, p=.06$, qualified by a Focus $\times$ Gender interaction, $F(1,84)=6.57, p<.02$. Women felt considerably 
more causally uncertain in the dispositional, as compared to the contextual, focus condition $(M=8.84$ vs. 6.85$)$, pairwise $F(1,84)=7.72, p<.007$. No focus effect was found for men $(M=6.52$ vs. 6.79$)$, pairwise $F(1,84)=0.19, p>.89$.

\section{Discussion}

Study 3 highlighted the gender-specific nature of contextual influences on certainty (see also Lenney, 1977). Results support our information-processing expertise model: Women were more causally certain when framing facilitated contextual thinking but less certain when framing primed dispositional thinking, an information-processing style for which they are less likely to possess a rich conceptual structure. Dispositionally focused women were less certain than contextually focused women and men, no matter what their focus of comparison.

\section{General Discussion}

There is an extensive literature demonstrating that in many domains of achievement women face a variety of obstacles that limit their chances for professional and academic success (e.g., Chaffins, Forbes, Fuqua, \& Cangemi, 1995; Quinn \& Spencer, this issue; Unger \& Crawford, 1992). Although overt discrimination and stereotyping clearly blocks women from achieving at the same level as men, in this article we have explored an obstacle of a more subtle nature. We proposed that gender-differentiated achievement outcomes may be due in part to the interplay between the dominant individualistic cultural frame and gender-specific self-views and preferred processing styles. In Western countries, the dominant cultural focus on individuals and their traits rather than situations, relationships, and circumstances, as the underlying causes of behavior (J. G. Miller, 1984; Morris \& Peng, 1994; Shweder \& Bourne, 1984), implies that fixed abilities rather than situations and contextual factors are key to understanding individual success or failure. We proposed that this dominant cultural focus can match, or mismatch, with how the self is organized, matching with men's independence-focused self-schemas and mismatching with women's interdependence-focused self-schemas (Cross \& Madson, 1997; Markus \& Oyserman, 1989).

These differences in matching between cognitive style and dominant cultural frame lead to differential vulnerability for men and women exposed to downward social comparisons in the academic domain. Because of their emphasis on personal independence, men are more likely to contrast the self and the other, assuming the self to be unique and different from the failed other. By contrast, women's interdependent self-schemas will direct attention to social contexts as causes of success and failure, providing rich cognitive resources for warding off the dispiriting effects of another's failure when contextual processing is primed. But women are not always able to avoid the negative impact of another's failure on the self. In 
individualistic, independence-focused societies, it is normative to see achievement as based on traits or stable dispositions. For women, thinking dispositionally is likely to mean processing information like a "novice," that is, without a richly developed knowledge structure to facilitate information processing. As a result, women are more likely to assimilate the failure of a personally relevant other into their own self-view than men. This reduces women's belief that they will be able to use efficacious strategies or attain positive academic possible selves, reducing persistence, and, ultimately, performance. As proposed in the introduction, this can lead to the apparent confirmation of gender stereotypes, because women with negative possible selves are more likely to confirm the negative expectations that others have for them. The possible result is the continued stigmatization of women as less able and less competent.

We demonstrated, however, that rather than reflecting a general consequence of women's self-construals, the downward comparison effect is contingent on processing focus. Women were most likely to assimilate the other's failure into their self-judgments when processing focus was dispositional, arguably a default mode of person perception in Western cultures (e.g., Shweder \& Bourne, 1984). Using an expertise metaphor, we argued that whereas men are more efficient in manipulating dispositional information, women are more efficient in manipulating situational information. Thus when situational information is made salient, men as novice manipulators of this information simply assimilate it, just as women assimilate dispositional information. In other words, both men and women show assimilation, but in differing circumstances. Generally, when factors made relevant are not in one's domain of expertise, one will be less successful in shielding one's self-concept from relevant but detrimental comparison information.

\section{Why Does the Western Cultural Frame More Closely Resemble Men's Self-Structures?}

The greater congruence between men's self-construals and the Western cultural frame is potentially the result of the dominant influence that men have had and continue to have in many important areas of Western society. In other words, the imbalances in social power between the genders may have contributed to a link between gender socialization, with men focusing on independence and boundedness of the self, and the cultural emphasis on individualism. In particular, men may have helped shape and propagate cultural representations that champion individualistic values and practices. Since the influence of women on the public sphere and other arenas of societal power has been limited in Western society (e.g., MacKinnon, 1987; Vianello, 1990), it is not surprising to find a discrepancy between localized patterns of female gender role socialization and the central values of Western cultures. 
Gendered differences in focus of self-construals can make matching the personal and the social more difficult for women. Since gender socialization occurs within a given culture, however, men and women share this social reality, at least to a degree. Women understand cultural individualism and participate in the culture but must find bridges between their self-construals and the social context. Men and women differ in the extent they care for and regard the self as emotionally related to others. This gender difference has been termed "relatedness" (Kashima et al., 1995) and "communion" (Bakan, 1966; Gabriel \& Gardner, 1999) and may be stable across individualist and collectivist cultures (Kashima et al., 1995), as well as within U.S. racial-ethnic groups (Coon \& Kemmelmeier, 2000).

\section{Gender and Social Comparison}

Ample evidence that men and women process interpersonal information differently (see Cross \& Madson, 1997) has as yet spurred little information about gender differences in downward social comparisons (see Gibbons \& McCoy, 1991, for an exception). This is surprising, because individual goals and cognitive habits have profound implications for the social-comparison process (e.g., Wood $\&$ Taylor, 1991). Our results emphasize the role of gender and the nature of self-construals as a moderator of the consequences of social comparison. Contrary to earlier "fear of success" researchers, however, we are not suggesting a gender difference in motivation to protect and enhance self-esteem (Horner, 1972; Monahan, Kuhn, \& Shaver, 1974). Rather, we propose that men and women strive equally to attain a positive sense of self, differing only in the efficiency with which this goal is achieved in varying circumstances. In a dispositional frame-dominated culture such as the United States, women are likely to be disadvantaged in their ability to shield the self from the failure of others.

\section{References}

Acitelli, L. K. (1993). Gender differences in relationship awareness and marital satisfaction among young married couples. Personality and Social Psychology Bulletin, 18, 102-110.

Bakan, D. (1966). The duality of human existence. Boston: Beacon Press.

Beyer, S. (1990). Gender differences in the accuracy of self-evaluations of performance. Journal of Personality and Social Psychology, 59, 960-970.

Bornholt, L., Goodnow, J., \& Cooney, G. (1994). Influences of gender stereotypes on adolescents' perceptions of their own achievement. American Educational Research Journal, 31, 675-692.

Brickman, P., \& Bulman, R. (1977). Pleasure and pain in social comparison. In J. Suls \& R. Miller (Eds.), Social comparison processes: Theoretical and empirical perspectives (pp. 149-186). Washington, DC: Hemisphere.

Brown, J., \& Dutton, K. (1995). Truth and consequences: The costs and benefits of self-knowledge. Personality and Social Psychology Bulletin, 21, 1288-1296.

Buunk, B., \& Ybema, J. (1997). Social comparisons and occupational stress: The identificationcontrast model. In B. Buunk \& F. Gibbons (Eds.), Health, coping, and well-being: Perspectives from social comparison theory (pp. 359-388). Mahwah, NJ: Erlbaum. 
Catrambone, P., \& Markus, H. (1987). The role of self-schemas in going beyond the information given. Social Cognition, 5, 349-368.

Chaffins, S., Forbes, M., Fuqua, H. E. Jr., \& Cangemi, J. P. (1995). The glass ceiling: Are women where they should be? Education, 115, 380-386.

Coon, H., \& Kemmelmeier, M. (2000). Cultural orientations in the United States: (Re-)Examining differences among ethnic/racial groups. Manuscript submitted for publication.

Cross, S., \& Madson, L. (1997). Models of the self: Self-construals and gender. Psychological Bulletin, 122, 5-37.

Dunn, J., Bretherton, I., \& Munn, P. (1987). Conversations about feeling states between mothers and their young children. Developmental Psychology, 23, 132-139.

Festinger, L. (1954). A theory of social comparison processes. Human Relations, 7, 117-140.

Gabriel, S., \& Gardner, W. L. (1999). Are there "his" and "hers" type of interdependence? The implications of gender differences in collective versus relational interdependence for affect, behavior, and cognition. Journal of Personality and Social Psychology, 77, 642-655.

Gibbons, F. X., \& McCoy, S. B. (1991). Self-esteem, similarity, and reactions to active versus passive downward comparison. Journal of Personality and Social Psychology, 60, 414-424.

Gilbert, D. T., Giesler, R. B., \& Morris, K. A. (1995). When comparisons arise. Journal of Personality and Social Psychology, 69, 227-236.

Gilligan, C. (1982). In a different voice: Psychological theory and women's development. Cambridge, MA: Harvard University Press.

Goethals, G., Messick, D. M., \& Allison, S. T. (1991). The uniqueness bias: Studies of constructive comparison. In J. Suls \& T. A. Wills (Eds.), Social comparison: Contemporary theory and research (pp. 149-176). Hillsdale, NJ: Erlbaum.

Hakmiller, K. L. (1966). Threat as a determinant to downward comparison. Journal of Experimental Social Psychology (Suppl. 1), 32-39.

Halperin, S. (1998). Summary. In S. Halperin (Ed.), The forgotten half revisited (pp. i-viii). Washington, DC: American Youth Policy Forum.

Heatherington, L., Daubman, K. A., Bates, C., Ahn, A., Brown, H., \& Preston, C. (1993). Two investigations of "female modesty" in achievement situations. Sex Roles, 29, 739-754.

Helgeson, V. S. (1994). Relation of agency and communion to well-being: Evidence and potential explanations. Psychological Bulletin, 116, 412-428.

Horner, M. S. (1972). Toward an understanding of achievement-related conflicts in women. Journal of Social Issues, 28, 157-175.

Ickes, W., Robertson, E., Tooke, W., \& Teng, G. (1986). Naturalistic social cognition: Methodology, assessment, and validation. Journal of Personality and Social Psychology, 51, 66-82.

Josephs, R. A., Markus, H., \& Tafarodi, R. W. (1992). Gender and self-esteem. Journal of Personality and Social Psychology, 63, 391-402.

Kashima, Y., Yamaguchi, S., Kim, U., Choi, S., Gelfand, M. J., \& Yuki, M. (1995). Culture, gender, and self: A perspective from individualism-collectivism research. Journal of Personality and Social Psychology, 69, 925-937.

Lenney, E. (1977). Women's self-confidence in achievement settings. Psychological Bulletin, 84, $1-13$.

Lenney, E. (1981). What's fine for the gander isn't always good for the goose: Sex differences in self-confidence as a function of ability area and comparison others. Sex Roles, 7, 905-923.

Lenney, E., Gold, J., \& Browning, C. (1983). Sex differences in self-confidence: The influence of comparison to others' ability level. Sex Roles, 9, 925-942.

Lykes, M. B. (1985). Gender and individualistic vs. collectivistic bases for notions about the self. Journal of Personality, 53, 356-383.

Maccoby, E. E., \& Jacklin, C. N. (1974). The psychology of sex differences. Stanford, CA: Stanford University Press.

MacKinnon, C. A. (1987). Feminism unmodified. Cambridge, MA: Harvard University Press.

Markus, H. R. (1977). Self-schemata and processing information about the self. Journal of Personality and Social Psychology, 35, 63-78.

Markus, H. R., \& Oyserman, D. (1989). Gender and thought: The role of the self. In M. Crawford \& M. Hamilton (Eds.), Gender and thought (pp. 100-127). New York: Springer. 
Markus, H. R., \& Sentis, K. P. (1982). The self in social information processing. In M. J. Suls (Ed.), Psychological perspectives on the self (Vol. 1, pp. 41-70). Hillsdale, NJ: Erlbaum.

Markus, H. R., Smith, J., \& Moreland, R. (1985). Role of the self-concept in the perception of others. Journal of Personality and Social Psychology, 49, 1494-1512.

Miller, J. G. (1984). Culture and the development of everyday social explanation. Journal of Personality and Social Psychology, 46, 961-978.

Miller, L. S. (1995). An American imperative: Accelerating minority educational advancement. London: Yale University Press.

Monahan, L., Kuhn, D., \& Shaver, P. (1974). Intrapsychic versus cultural explanations of the "fear of success" motive. Journal of Personality and Social Psychology, 29, 60-64.

Morris, M., \& Peng, K. (1994). Culture and cause: American and Chinese attributions for social and physical events. Journal of Personality and Social Psychology, 67, 949-971.

Norenzayan, A., Choi, I., \& Nisbett, R. E. (2000). Eastern and Western perceptions of causality for social behavior: Lay theories about personalities and situations. In D. A. Prentice \& D. T. Miller (Eds.), Cultural divides: Understanding and overcoming group conflict (pp. 239-272). New York: Russell Sage Foundation.

Oyserman, D., Coon, H., \& Kemmelmeier, M. (2000). How American is individualism? Relational Americans and other lessons from cultural and cross-cultural research. Unpublished manuscript, University of Michigan, Ann Arbor.

Oyserman, D., \& Markus, H. (1990). Possible selves and delinquency. Journal of Personality and Social Psychology, 59, 112-125.

Oyserman, D., \& Markus, H. R. (1993). The sociocultural self. In M. J. Suls (Ed.), Psychological perspectives on the self (Vol. 4, pp. 187-220). Hillsdale, NJ: Erlbaum.

Oyserman, D., \& Saltz, E. (1993). Competence, delinquency, and attempts to attain possible selves. Journal of Personality and Social Psychology, 65, 360-374.

Pelham, B. W., \& Wachsmuth, J. O. (1995). The waxing and waning of the social self: Assimilation and contrast in social comparison. Journal of Personality and Social Psychology, 69, 825-838.

Roberts, T. (1991). Gender and the influence of evaluations on self-assessments in achievement situations. Psychological Bulletin, 109, 297-308.

Sampson, E. E. (1977). Psychology and the American ideal. Journal of Personality and Social Psychology, 35, 767-782.

Schwalbe, M., \& Staples, C. (1991). Gender differences in sources of self-esteem. Social Psychology Quarterly, 54, 158-168.

Schwarz, N. (1995). Social cognition: Information accessibility and use in social judgment. In E. E. Smith \& D. N. Osherson (Eds.), Thinking: An invitation to cognitive science (Vol. 3, 2nd ed., pp. 345-376). Cambridge, MA: MIT Press.

Shweder, R. A., \& Bourne, L. (1984). Does the concept of the person vary cross-culturally? In R. Shweder \& R. Levine (Eds.), Culture theory: Essays on mind, self, and emotion (pp. 158-190). New York: Cambridge University Press.

Sleeper, L. A., \& Nigro, G. N. (1987). It's not who you are but who you're with: Self-confidence in achievement settings. Sex Roles, 16, 57-69.

Stein, A. H., Pohly, S. R., \& Mueller, E. (1971). The influence of masculine, feminine, and neutral tasks on children's achievement behavior, expectancies of success, and attainment values. Child Development, 42, 195-207.

Stevenson, H. W., \& Stigler, J. W. (1992). The learning gap: Why our schools are failing and what we can learn from Japanese and Chinese education. New York: Summit.

Suls, J., Gaes, G., \& Gastorf, J. (1979). Evaluation a sex-related ability: Comparison with same-, opposite-, and combined-sex norms. Journal of Research in Personality, 13, 294-304.

Tesser, A. (1988). Toward a self-evaluation maintenance model of social behavior. In L. Berkowitz (Ed.), Advances in experimental social psychology (Vol. 21, pp. 181-227). San Diego, CA: Academic.

Tesser, A., \& Campbell, J. (1980). Self-definition: The impact of the relative performance and similarity of others. Social Psychology Quarterly, 43, 341-347.

Trafimow, D., Triandis, H. C., \& Goto, S. G. (1991). Some tests of the distinction between the private self and the collective self. Journal of Personality and Social Psychology, 60, 649-655.

Triandis, H. C. (1995). Individualism and collectivism. Boulder, CO: Westview. 
Trope, Y. (1986). Self-assessment and self-enhancement in achievement motivation. In R. M. Sorrentino \& E. T. Higgins (Eds.), Handbook of motivation and cognition: Foundations of social behavior (Vol. 1, pp. 350-378). New York: Guilford.

Unger, R., \& Crawford, M. (1992). Women and gender: A feminist psychology. Philadelphia: Temple University Press.

Vianello, M. (1990). Gender inequality: A comparative study of discrimination and participation. London: Sage.

Watkins, D., Akande, A., Fleming, J., Ismail, M., Lefner, K., Regmi, M., Watson, S., Yu, J., Adair, J., Cheng, C., Gerong, A., McInerney, D., Mpofu, E., Singh-Sengupta, S., \& Wondimu, H. (1998). Cultural dimensions, gender, and the nature of self-concept: A fourteen-country study. International Journal of Psychology, 33, 17-31.

Weary, G., \& Edwards, J. A. (1994). Individual differences in causal uncertainty. Journal of Personality and Social Psychology, 67, 308-318.

Weiner, B., Frieze, I., Kukla, A., Reed, L., Rest, S., \& Rosenbaum, R. M. (1987). Attribution: Perceiving the causes of behavior. Hillsdale, $\mathrm{NJ}$ : Erlbaum.

Wills, T. A. (1981). Downward social comparison principles in social psychology. Psychological Bulletin, 90, 245-271.

Wood, J., \& Taylor, K. (1991). Serving self-relevant goals through social comparison. In J. Suls \& T. Wills (Eds.), Social comparison: Contemporary theory and research (pp. 23-49). Hillsdale, NJ: Erlbaum.

Zuckerman, D. M. (1985). Confidence and aspirations: Self-esteem and self-concepts as predictors of students' life goals. Journal of Personality, 53, 543-560.

MARKUS KEMMELMEIER is a PhD candidate in the Social Psychology program at the University of Michigan. He holds a diploma in Psychology from the University of Mannheim, Germany, and an MA in Psychology from the University of Michigan. His research interests are in the psychology of self and social identity as a function of its cultural and political context. He also studies the cultural reproduction of societal hierarchy and its implications for prejudice and discrimination.

DAPHNA OYSERMAN is an Associate Research Scientist at the Research Center for Group Dynamics, Institute for Social Research, and an Associate Professor in the Department of Psychology and School of Social Work at the University of Michigan. Her research focuses on the interplay between cultural contexts, identity and the sense individuals make of their possibilities and the strategies likely to help them attain their life goals. Currently she is studying the influence of racial- and ethnic-minority identity schemas on sensitivity to stereotyping and engagement in school among adolescents and responses to everyday discrimination experiences among community adults. Research funded by the National Institute of Mental Health includes a racial-identity-focused preventive intervention aimed at promoting school persistence and reducing dropout. 